\title{
Pharmacokinetics of Bevacizumab in Three Patients Under the Age of 3 Years with CNS Malignancies
}

\author{
Johannes Gojo ${ }^{1}$ - Robert Sauermann ${ }^{2,3}$ - Ursula Knaack ${ }^{1}$ - Irene Slave ${ }^{1}$ • \\ Andreas Peyrl ${ }^{1}$ (D)
}

Published online: 2 June 2017

(c) The Author(s) 2017. This article is an open access publication

\begin{abstract}
Background Bevacizumab is a recombinant antibody that is increasingly used in pediatric malignancies. The pharmacokinetics of bevacizumab in pediatric patients have been shown to be influenced by tumor localization and body weight. In this report, we present data on the pharmacokinetics and safety of bevacizumab in children under the age of 3 years with central nervous system (CNS) malignancies.

Methods Three patients (mean age 22 months) were treated with intravenous bevacizumab $10 \mathrm{mg} / \mathrm{kg}$ every 2 weeks. In total, 20 trough and peak bevacizumab concentrations of 10 treatment cycles were obtained at steady state.

Results Bevacizumab was generally well-tolerated in this age group. The mean trough concentration was $127 \pm 29 \mu \mathrm{g} / \mathrm{ml}$ (range 77-155), and the mean peak concentration was $149 \pm 13 \mu \mathrm{g} / \mathrm{ml}$ (range 113-157). Trough and peak levels were stable upon repeated treatment cycles in the same patient. In contrast, we determined strong interindividual variations in trough levels. Whereas the plasma concentration of the oldest patient matched the prediction of a previously published model, younger patients showed markedly higher trough levels.
\end{abstract}

Andreas Peyrl

andreas.peyrl@meduniwien.ac.at

1 Department of Pediatrics, Medical University of Vienna, Waehringer Guertel 18-20, 1090 Vienna, Austria

2 Department of Clinical Pharmacology, Medical University of Vienna, Vienna, Austria

3 Main Association of Austrian Social Security Institutions, Vienna, Austria
Conclusions Serum peak concentrations of bevacizumab in children under the age of 3 years with CNS malignancies are in a similar magnitude to that found in older children and adults. Thus, a dosing schedule of bevacizumab $10 \mathrm{mg} / \mathrm{kg}$ every 2 weeks can be considered sufficient and safe, even in very young children. We further show that very young children with CNS malignancies show a markedly reduced plasma clearance, possibly related to lower body weight or differences in clearance mechanisms of antibodies.

\section{Key points}

Bevacizumab was generally well-tolerated in children under the age of 3 years and can be considered safe in this age group.

Peak serum concentrations of bevacizumab were of a similar magnitude to that found in older children and adults.

Plasma clearance was markedly reduced in patients of lower age and body weight.

\section{Introduction}

Bevacizumab, a recombinant humanized monoclonal immunoglobulin ( $\mathrm{Ig}$ ) G1 antibody, is an angiogenesis inhibitor that prevents endothelial cell proliferation and new blood vessel formation by binding vascular endothelial growth factor (VEGF) and inhibiting the interaction of 
VEGF with its receptors on the surface of endothelial cells [1]. It is increasingly applied in the treatment of pediatric central nervous system (CNS) malignancies, especially in recurrent tumors [2-5]. Moreover, in children with optic pathway gliomas, treatment with bevacizumab has resulted in the recovery of vision [6].

Pharmacokinetics, including drug absorption, distribution, metabolism, and elimination may differ greatly between children and the adult population, mainly because of variations in body composition and distinctive functions of liver, kidneys, and other organs [7]. Human growth is not a linear process, age-associated changes in body composition and organ function are dynamic, and major physiological changes occur during the first decade of life [8]. Dose adjustments in the pediatric population based on body weight (BWT) or body surface area (BSA), without considering developmental growth, may be inappropriate since BWT or BSA do not represent the true nature of overall organ function in children [9]. Notably, the factors that substantially influence the pharmacokinetics of drugs are physiological (tissue volumes and blood flow rates, renal and biliary excretion), physicochemical (tissue-blood partition coefficients), and biochemical (rates of xenobiotic metabolism) [7].

Consequently, pharmacokinetic studies in a given appropriate age group are indispensable for safe and effective drug therapy for children. Only recently, a population pharmacokinetic modeling of bevacizumab based on different clinical studies in children with both sarcomas and CNS malignancies has been elaborated [10]. The final model included BWT, serum albumin, gender, and tumor localization. Thereby, the authors showed that bodyweightdependent bevacizumab dosing is safe across all age groups. Interestingly, the clearance (CL) of bevacizumab in patients with CNS tumors was described to be markedly lower compared with sarcoma patients. The study population also included 12 children under the age of 3 years, but patients with CNS tumors and patients with sarcomas were not analyzed separately. Thus, further data from this particular age group of pediatric patients with CNS malignancies are of special interest. In this study, we present data on the pharmacokinetics and safety of bevacizumab in children under the age of 3 years with CNS tumors.

\section{Patients and Methods}

\subsection{Patients and Eligibility Criteria}

All patients were treated with intravenously administered bevacizumab for therapeutic reasons. Other eligibility criteria included (1) life expectancy of at least 8 weeks; (2) written informed consent from parents; (3) serum creatinine $<1.5 \mathrm{mg} / \mathrm{dl}$; (4) total serum bilirubin $<2.0 \mathrm{mg} / \mathrm{dl}$ and alanine aminotransferase (ALT) $<5 \times$ the upper limit of normal; and (5) platelet count $>40,000 / \mathrm{mm}^{3}$ within $48 \mathrm{~h}$ before the first treatment.

The study protocol was approved by the Ethics Committee of the Medical University of Vienna and registered in the European Clinical Trials Database (EudraCT Number 2009-013024-23). Patient history and physical examination, including height, weight, blood pressure, and laboratory tests (including urine stix), were obtained prior to initiation of treatment and at every administration of bevacizumab thereafter. Cranial magnetic resonance imaging (MRI) with and without contrast was obtained before the first treatment and every 3 months thereafter, as well as basal hormone levels (thyroid-stimulating hormone [TSH], free T4 [fT4], luteinizing hormone [LH], folliclestimulating hormone [FSH], cortisol), since hypothyroidism is a known side effect of bevacizumab in children [11].

\subsection{Drug Administration and Pharmacokinetic Study}

Bevacizumab was administered as an intravenous infusion at a dose of $10 \mathrm{mg} / \mathrm{kg}$ over $30 \mathrm{~min}$, every 2 weeks.

For the pharmacokinetic study, approximately $1.2 \mathrm{ml}$ of venous blood was collected into tubes without added anticoagulant before and immediately after administration of bevacizumab. Due to the long half-life $\left(t_{1 / 2}\right)$ of bevacizumab, two measurement time points per dosing interval at steady state were considered adequate to determine whether sufficient drug concentrations were reached in young children, with the given dosing regimen. Moreover, it was considered ethically appropriate to minimize the number of blood samples in infants with tumors. Blood samples were kept on ice for a maximum of $60 \mathrm{~min}$ and were then centrifuged at $+4{ }^{\circ} \mathrm{C}$ and $3000 \mathrm{rpm}$ for $10 \mathrm{~min}$; cells were discharged and serum was obtained. Serum was snap frozen at $-20{ }^{\circ} \mathrm{C}$. Thereafter, samples were stored at approximately $-80{ }^{\circ} \mathrm{C}$ until analysis.

\subsection{Bioanalytical Assay and Pharmacokinetic Data Analysis}

Bevacizumab concentrations were determined using an enzyme-linked immunosorbent assay (ELISA), according to the manufacturer's instructions. Briefly, snap-frozen serum aliquots were thawed on ice before they were subjected to analysis in triplicate. The minimum quantifiable concentration in human serum was $30 \mathrm{ng} / \mathrm{mL}$ (Matriks Biotech, Ankara, Turkey), and detected values were validated with a calibration curve. Trough and peak 
concentrations at steady state were available from two children from four therapy cycles, and from one child from two therapy cycles. Thus, 20 pharmacokinetic samples from a total of 10 therapy cycles at steady state could be analyzed.

Due to the limited number of sampling time points and known pharmacokinetic properties (long $t_{1 / 2}$ ) of bevacizumab, the following estimations were performed (from non-fitted data): the equation $\left[\ln \left(C_{1}\right)-\ln \left(C_{2}\right)\right] /$ dosing interval $\tau$ was employed to calculate the individual elimination rate constant $k_{\mathrm{el}}$ (using corresponding values of $C_{\text {peak,ss }}$ as $C_{1}$, and $C_{\text {trough,ss }}$ as $C_{2}$ ) at steady state. Bevacizumab concentrations were considered steady state if patients had received at least four previous cycles of bevacizumab before pharmacokinetic study samples were obtained. The equation $\ln (2) / k_{\mathrm{el}}$ was used to determine plasma $t_{1 / 2}$ of bevacizumab at steady state. The area under the concentration-time curve (AUC) during one dosing interval $\tau$ at steady state $\left(\mathrm{AUC}_{\tau, \mathrm{ss}}\right)$ was calculated using the linear trapezoidal rule as $\tau \times\left(C_{\text {peak,ss }}+C_{\text {trough,ss }}\right) / 2$, as well as the logarithmic trapezoidal method. Unless indicated otherwise, values are presented as mean \pm standard deviation.

Serum albumin concentrations of all treatment cycles were available, and the pharmacokinetics of these cycles were calculated according to a previously published model [10].

\subsection{Assessment of Toxicity}

Toxicities were evaluated in a prospective manner and assessment was performed at least every 2 weeks or as necessary. Adverse events were graded based on the Common Terminology Criteria for Adverse Events v.3.0. Patients were considered assessable for toxicity if they received at least one dose of bevacizumab.

\section{Results}

\subsection{Patients}

Pharmacokinetic studies were performed in a total of three female children under the age of 3 years $(11,25$, and 31 months at first administration) who were treated with $10 \mathrm{mg} / \mathrm{kg}$ bevacizumab every 2 weeks. Details of the clinical characteristics are provided in Table 1.

Two of the patients (25 and 31 months of age) with neurofibromatosis type 1 and optic pathway gliomas were treated with carboplatin/vincristine according to the LGG2004 trial [12], augmented with bevacizumab to preserve vision. One patient with malignant rhabdoid tumors in the kidney and brain was treated with nephrectomy and conventional chemotherapy [13]. After repeated progressions, the patient was switched to a metronomic anti-angiogenic regimen including bevacizumab [2].

\subsection{Toxicity}

Bevacizumab was generally well-tolerated with the administered dose of $10 \mathrm{mg} / \mathrm{kg}$ in this age group. Since all patients received concurrent systemic chemotherapy, the toxicity of bevacizumab could not be assessed independently. No tumor hemorrhages were observed. Side effects occurring during the treatment period with bevacizumab and chemotherapy included neutropenia in $1 / 3$ patients (grade IV), proteinuria in $2 / 3$ patients (grade I), hematuria in $1 / 3$ patients (grade I), and new onset hypothyroidism in $1 / 3$ patients. In one patient with optic pathway gliomas, a wound-healing complication of her central venous access device occurred after bevacizumab administration 1 day after implantation. Additionally, the patient with malignant rhabdoid tumors in the kidney and brain developed hypertension (grade II). Serial height measurements of the two children with optic pathway tumors showed consistent progression along their percentile curve, while the patient with malignant rhabdoid tumors in the kidney and brain exhibited a decline in growth 18 months after initiating bevacizumab, when she was already terminally ill.

\subsection{Pharmacokinetics}

The patients received repeated bevacizumab doses of $10 \mathrm{mg} / \mathrm{kg}$. The previous infusion of bevacizumab was always approximately 14 days (range 10-15) before study sampling and study drug administration were performed. Trough and peak samples (before and after infusion of bevacizumab) were available from all three children before and after intravenous administration of bevacizumab at steady state.

After doses of $10 \mathrm{mg} / \mathrm{kg}$ every 2 weeks, bevacizumab concentrations were relatively stable throughout the dosing interval of 2 weeks. Overall, the mean peak concentration after intravenous drug administration was $149 \pm 13 \mu \mathrm{g} / \mathrm{ml}$ (range 113-157) at steady state, and the mean trough concentration 2 weeks after the last drug administration was $127 \pm 29 \mu \mathrm{g} / \mathrm{ml}$ (range 77-155).

The mean $\mathrm{AUC}_{\tau, \mathrm{ss}}$ was estimated to be $1810 \pm 258 \mu \mathrm{g} /$ $\mathrm{ml} \times \mathrm{d}$ (day). When using the logarithmic trapezoidal rule, a similar value of $1796 \pm 272 \mu \mathrm{g} / \mathrm{ml} \times \mathrm{d}$ was calculated. In this small sample size, the median $t_{1 / 2}$ at steady state of all three children was calculated to be 77 days (range 15-574).

In a next step, we compared our results with a previously published model of pediatric bevacizumab pharmacokinetics [10]. Therefore, we predicted the CL for each 
Table 1 Clinical characteristics of patients

\begin{tabular}{|c|c|c|c|c|c|c|}
\hline $\begin{array}{l}\text { Patient } \\
\text { number }\end{array}$ & Diagnosis & $\begin{array}{l}\text { Age at first } \\
\text { administration of } \\
\text { bevacizumab, months }\end{array}$ & $\begin{array}{l}\text { Age at first PK } \\
\text { sampling, } \\
\text { months }\end{array}$ & $\begin{array}{l}\text { Weight at first } \\
\text { PK sampling, } \\
\text { kg }\end{array}$ & $\begin{array}{l}\text { Height at first } \\
\text { PK sampling, } \\
\mathrm{cm}\end{array}$ & $\begin{array}{l}\text { Overall number of } \\
\text { bevacizumab } \\
\text { applications }\end{array}$ \\
\hline 1 & $\begin{array}{l}\text { Rhabdoid syndrome- } \\
\text { ATRT (brain), RTK } \\
\text { (kidney) }\end{array}$ & 11 & 17 & $\begin{array}{l}8(<3 . \\
\text { percentile })\end{array}$ & $\begin{array}{l}75(10 . \\
\text { percentile })\end{array}$ & 40 \\
\hline 2 & $\begin{array}{l}\text { Optic pathway glioma } \\
\text { (NF1) }\end{array}$ & 31 & 33 & $\begin{array}{l}16(90 . \\
\text { percentile })\end{array}$ & $\begin{array}{l}99(90 . \\
\text { percentile })\end{array}$ & 18 \\
\hline 3 & $\begin{array}{l}\text { Optic pathway glioma } \\
\text { (NF1) }\end{array}$ & 25 & 29 & $\begin{array}{l}11 \text { (10. } \\
\text { percentile) }\end{array}$ & $\begin{array}{l}89(10 . \\
\text { percentile })\end{array}$ & 36 \\
\hline
\end{tabular}

$A T R T$ atypical teratoid rhabdoid tumor, $R T K$ rhabdoid tumor of the kidney, $N F 1$ neurofibromatosis type $1, P K$ pharmacokinetic

peak concentration according to this model, taking into account BWT and serum albumin levels (ALBU). All three patients had serum albumin levels in the normal range, without significant differences between the patients (mean $3.81 \mathrm{~g} / \mathrm{dl} \pm 0.28 ; p=0.14)$. The applied formula was $\mathrm{CL}_{\mathrm{i}}=9.9 \times\left(\mathrm{BWT}_{\mathrm{i}} / 70\right)^{0.75} \times\left(\mathrm{ALBU}_{\mathrm{i}} / 39\right)^{-0.3} \times 0.725$.

The obtained concentration curves were then plotted against the actually measured bevacizumab serum concentrations, including an additional time point after 7 days in one patient (Fig. 1). Interestingly, the oldest patient (patient 2) matched the model, whereas trough concentrations of the two younger patients (patients 1 and 3) were higher than expected from the model prediction, indicating a markedly reduced CL of bevacizumab in very young children with CNS malignancies compared with the model prediction.

\section{Discussion}

Bevacizumab has demonstrated activity and safety in the treatment of childhood brain tumors [2-6]. The purpose of the present study was to evaluate the pharmacokinetics and

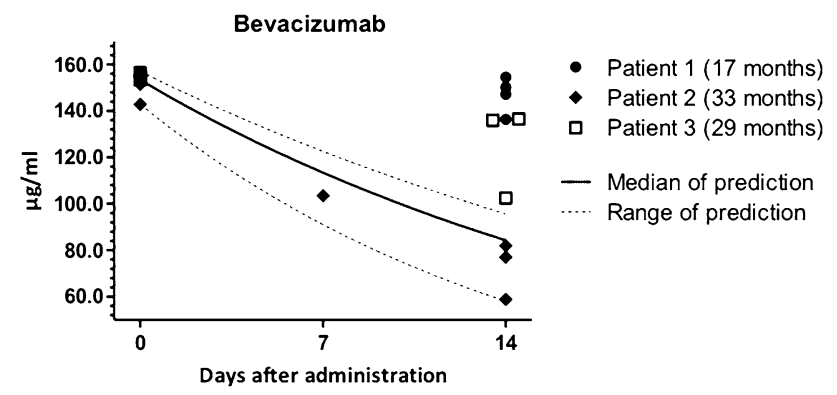

Fig. 1 Comparison of measured bevacizumab serum levels to modeled pharmacokinetics from a previous population pharmacokinetic study. Symbols depict measured peak and trough bevacizumab levels of patients 1-3 at given time points. Lines depict mean and range of bevacizumab levels predicted by calculation using peak level, serum albumin, and bodyweight with a previously published model for bevacizumab pharmacokinetics [10] safety of bevacizumab in children under 3 years of age with CNS malignancies.

The metabolism and elimination of bevacizumab is similar to endogenous $\operatorname{IgG}$, i.e. primarily via proteolytic catabolism throughout the body, involving non-specific elimination pathways such as the neonatal $\mathrm{Fc}$ receptor and target-mediated elimination (e.g. VEGF-expressing endothelial cells in the case of bevacizumab). Therefore, CL of bevacizumab does not primarily rely on elimination through the kidneys and liver [14-17].

Studies on the metabolism and elimination of monoclonal antibodies in infants have rarely been conducted. The pharmacokinetics of humanized monoclonal antibodies in premature infants and term infants is best studied for respiratory syncytial virus (RSV)-neutralizing antibodies. Compared with adults, the pharmacokinetic data of both premature infants and infants showed a similar $t_{1 / 2}$ of RSVneutralizing antibodies after intravenous application of approximately 20 days $[18,19]$.

Furthermore, pharmacokinetic studies of bevacizumab in adult patients have demonstrated a $t_{1 / 2}$ of approximately 18 days following administration of a single intravenous dose of bevacizumab [20-23]. Previous pediatric studies in older children revealed comparable results to adult patients. In the first pediatric pharmacokinetic study, conducted in a heterogeneous group of eight children with solid tumors and a broad age range, drug exposure of bevacizumab was proportional to dose, with a median $t_{1 / 2}$ value of 11.8 days [24], while a study of 27 children aged 7-18 years with osteosarcoma revealed a $t_{1 / 2}$ of 12.2 days [25]. Recently, in a larger cohort of 232 pediatric patients with a wide age range and either sarcomas or CNS malignancies, bevacizumab exposure was similar in the pediatric and adult populations, with a $t_{1 / 2}$ of 19.6 and 20 days, respectively [10]. Additionally, a populationbased pharmacokinetic model for bevacizumab has been proposed. The cohort of 232 patients also included 12 children under the age of 3 years. However, no separate calculations for children in this age group ( $<3$ years) with 
CNS tumors were conducted. This previous study revealed a marked difference in pharmacokinetics between sarcoma and CNS tumor patients (for the overall population, including all age groups), as well as a remarkable BWT effect in children under the age of 3 years [10]. The mechanisms underlying the observed differences in the pharmacokinetics of bevacizumab between sarcoma and CNS tumor patients remain enigmatic. Potential reasons for this include differences in tumor-induced inflammation, tumor burden, or concomitant medication [10].

Consequently, there is special interest for a detailed analysis of pharmacokinetics of bevacizumab in very young children with brain tumors. A limitation of our study is its small sample size, highlighting the necessity to focus on this group of patients. According to our knowledge, this is the first study that focused on serum concentrations of bevacizumab at steady state after multiple intravenous infusions of $10 \mathrm{mg} / \mathrm{kg}$ in children under the age of 3 years with CNS malignancies. It is notable that the peak serum concentrations were at a comparable level in all three children, and remained constant and similar between different therapeutic cycles within the patients (intraindividually) when steady-state had been reached. This is in agreement with the established pharmacokinetic properties of bevacizumab [10, 20-25].

Despite similar absolute peak serum concentrations, the $t_{1 / 2}$ of bevacizumab showed a broad range and was in the upper range of those reported from previous pharmacokinetic studies. Of interest, the longest $t_{1 / 2}$ was observed in the youngest child of our study. Furthermore, only the oldest child with the highest BWT matched the previously published model for bevacizumab pharmacokinetics in children [10], whereas the two younger patients showed a markedly lower CL. This effect might be due to an age- or BWT-dependent effect, or differences in CL mechanisms of antibodies.

Interestingly, despite the prolonged $t_{1 / 2}$, maximal serum concentrations remained on a comparable level with those of both other children in our study, as well as with the reported levels in previous studies including children and adults [10, 23-25].

\section{Conclusions}

The present data confirm that exposure to bevacizumab in children under the age of 3 years with CNS malignancies is similar to that found in older children and adults, and the toxicities were moderate and comparable with previous reports [22-25]. Thus, a dosing schedule of $10 \mathrm{mg} / \mathrm{kg}$ every 2 weeks can be considered sufficient, adequate, and safe, even in very young children. These results are important as bevacizumab is an effective treatment in order to preserve vision in patients with optic pathway gliomas, a disease frequently affecting very young children [6]. Therefore, bevacizumab is likely to be more widely applied in very young children in the near future. In this context, our finding that this age group shows a prolonged $t_{1 / 2}$ of bevacizumab should be addressed in future clinical trials for bevacizumab treatment in pediatric CNS malignancies.

Acknowledgements This study was supported by 'Forschungsgesellschaft für cerebrale Tumore'.

\section{Compliance with ethical standards}

Conflicts of interest Johannes Gojo, Robert Sauermann, Ursula Knaack, Irene Slavc, and Andreas Peyrl declare that they have no conflicts of interest.

Ethical approval The study protocol was approved by the Ethics Committee of the Medical University of Vienna and registered in the European Clinical Trials Database (EudraCT number 2009-01302423). All procedures performed involving human participants were in accordance with the ethical standards of the institutional research committee and with the 1964 Helsinki declaration and its later amendments or comparable ethical standards.

Informed consent Informed consent was obtained from the parents of all individual participants included in the study.

Open Access This article is distributed under the terms of the Creative Commons Attribution-NonCommercial 4.0 International License (http://creativecommons.org/licenses/by-nc/4.0/), which permits any noncommercial use, distribution, and reproduction in any medium, provided you give appropriate credit to the original author(s) and the source, provide a link to the Creative Commons license, and indicate if changes were made.

\section{References}

1. Papadopoulos N, Martin J, Ruan Q, Rafique A, Rosconi MP, Shi $\mathrm{E}$, et al. Binding and neutralization of vascular endothelial growth factor (VEGF) and related ligands by VEGF Trap, ranibizumab and bevacizumab. Angiogenesis. 2012;15:171-85.

2. Peyrl A, Chocholous M, Kieran MW, Azizi AA, Prucker C, Czech T, et al. Antiangiogenic metronomic therapy for children with recurrent embryonal brain tumors. Pediatr Blood Cancer. 2012;59:511-7.

3. Fangusaro J, Gururangan S, Poussaint TY, McLendon RE, OnarThomas A, Warren KE, et al. Bevacizumab (BVZ)-associated toxicities in children with recurrent central nervous system tumors treated with BVZ and irinotecan (CPT-11): a Pediatric Brain Tumor Consortium Study (PBTC-022). Cancer. 2013;119:4180-7.

4. Gururangan S, Fangusaro J, Poussaint TY, McLendon RE, OnarThomas A, Wu S, et al. Efficacy of bevacizumab plus irinotecan in children with recurrent low-grade gliomas: a Pediatric Brain Tumor Consortium study. Neuro Oncol. 2014;16:310-7.

5. Hwang EI, Jakacki RI, Fisher MJ, Kilburn LB, Horn M, Vezina $\mathrm{G}$, et al. Long-term efficacy and toxicity of bevacizumab-based therapy in children with recurrent low-grade gliomas. Pediatr Blood Cancer. 2013;60:776-82.

6. Avery RA, Hwang EI, Jakacki RI, Packer RJ. Marked recovery of vision in children with optic pathway gliomas treated with bevacizumab. JAMA Ophthalmol. 2014;132:111-4. 
7. Kearns GL, Abdel-Rahman SM, Alander SW, Blowey DL, Leeder JS, Kauffman RE. Developmental pharmacology: drug disposition, action, and therapy in infants and children. N Engl J Med. 2003;349:1157-67.

8. Kearns GL. Impact of developmental pharmacology on pediatric study design: overcoming the challenges. J Allergy Clin Immunol. 2000;106(3 Suppl):S128-38.

9. Mahmood I. Dosing in children: a critical review of the pharmacokinetic allometric scaling and modelling approaches in paediatric drug development and clinical settings. Clin Pharmacokinet. 2014;53:327-46.

10. Han K, Peyret T, Quartino A, Gosselin NH, Gururangan S, Casanova $\mathrm{M}$, et al. Bevacizumab dosing strategy in paediatric cancer patients based on population pharmacokinetic analysis with external validation. Br J Clin Pharmacol. 2016;81:148-60.

11. Reismüller B, Azizi AA, Peyrl A, Heinrich M, Gruber-Olipitz M, Luckner D, et al. Feasibility and tolerability of bevacizumab in children with primary CNS tumors. Pediatr Blood Cancer. 2010;54:681-6.

12. Gnekow AK, Kandels D, Walker DA, Perilongo G, Grill J, Stokland $\mathrm{T}$, et al. A randomized trial of intensification of induction-chemotherapy within a 10 months treatment-strategy on tumor response at 24 weeks and progression-free-survival in pediatric low grade glioma (LGG): preliminary results of the SIOP-LGG-2004-Working-Group. Neuro Oncol. 2014;16(Suppl 1):64.

13. Seeringer A, Bartelheim K, Kerl K, Hasselblatt M, Leuschner I, Rutkowski S, et al. Feasibility of intensive multimodal therapy in infants affected by rhabdoid tumors-experience of the EURHAB registry. Klin Padiatr. 2014;226:143-8.

14. Ternant D, Paintaud G. Pharmacokinetics and concentration-effect relationships of therapeutic monoclonal antibodies and fusion proteins. Expert Opin Biol Ther. 2005;5(Suppl 1):S37-47.

15. Lin YS, Nguyen C, Mendoza JL, Escandon E, Fei D, Meng YG, et al. Preclinical pharmacokinetics, interspecies scaling, and tissue distribution of a humanized monoclonal antibody against vascular endothelial growth factor. J Pharmacol Exp Ther. 1999;288:371-8.

16. Fox JA, Hotaling TE, Struble C, Ruppel J, Bates DJ, Schoenhoff MB. Tissue distribution and complex formation with $\operatorname{IgE}$ of an
anti-IgE antibody after intravenous administration in cynomolgus monkeys. J Pharmacol Exp Ther. 1996;279:1000-8.

17. Hakimi J, Chizzonite R, Luke DR, Familletti PC, Bailon P, Kondas JA, et al. Reduced immunogenicity and improved pharmacokinetics of humanized anti-Tac in cynomolgus monkeys. J Immunol. 1991;147:1352-9.

18. Subramanian KN, Weisman LE, Rhodes T, Ariagno R, Sánchez PJ, Steichen J, et al. Safety, tolerance and pharmacokinetics of a humanized monoclonal antibody to respiratory syncytial virus in premature infants and infants with bronchopulmonary dysplasia. MEDI-493 Study Group. Pediatr Infect Dis J. 1998;17:110-5.

19. Sáez-Llorens X, Moreno MT, Ramilo O, Sánchez PJ, Top FH Jr. Connor EM; MEDI-493 Study Group. Safety and pharmacokinetics of palivizumab therapy in children hospitalized with respiratory syncytial virus infection. Pediatr Infect Dis J. 2004;23:707-12.

20. Gordon MS, Margolin K, Talpaz M, Sledge GW Jr, Holmgren E, Benjamin R, et al. Phase I safety and pharmacokinetic study of recombinant human anti-vascular endothelial growth factor in patients with advanced cancer. J Clin Oncol. 2001;19:843-50.

21. Hsei V, Siguenza P, Gaudreault J. Effect of body weight on bevacizumab pharmacokinetics in cynomolgus monkeys and humans [abstract no. 1818]. Proc Am Soc Clin Oncol. 2002;21.

22. Hsei VC, Novotny WF, Margolin K, Gordon M, Small EJ, Griffing S, et al. Population pharmacokinetic (PK) analysis of bevacizumab (BV) in cancer subjects [abstract no. 272]. Proc Am Soc Clin Oncol. 2001;20.

23. Lu JF, Bruno R, Eppler S, Novotny W, Lum B, Gaudreault J. Clinical pharmacokinetics of bevacizumab in patients with solid tumors. Cancer Chemother Pharmacol. 2008;62:779-86.

24. Glade Bender JL, Adamson PC, Reid JM, Xu L, Baruchel S, Shaked Y, et al. Children's Oncology Group Study. Phase I trial and pharmacokinetic study of bevacizumab in pediatric patients with refractory solid tumors: a Children's Oncology Group Study. J Clin Oncol. 2008;26:399-405.

25. Turner DC, Navid F, Daw NC, Mao S, Wu J, Santana VM, et al. Population pharmacokinetics of bevacizumab in children with osteosarcoma: implications for dosing. Clin Cancer Res. 2014;20:2783-92. 